\title{
LA ESTROFA PURÍMICA - MOLDE DE COPLAS SEFARDÍES
}

\author{
Susana WEICH-SHAHAK
}

\begin{abstract}
The purimic-strophe, a traditional musico-poetic structure, has served to enrich the Judeo-Spanish repertoire, as a living and creative genre. Thus, to the corpus of Sephardic Coplas new coplas were added during the years of the Jews' exile in the Ottoman and in the Morocaan areas. This article, based on recording from my own fieldwork, deals precisely with the use of the purimic strophe as a structural model for themes that reflect the impact of social and historical circumstances on the individuum and his community. Among the them: customs, local and social changes, as well as political and historical events.
\end{abstract}

\section{Resumen}

La estrofa purímica, forma músico-poética tradicional, ha servido para enriquecer el repertorio de las Coplas Sefardíes, demostrando que éstas constituyen un género vivo, creativo en su misma esencia. Su Corpus se ha ensanchado hasta nuestros días con nuevas coplas que reflejan el impacto de las circunstancias sobre la vida del individuo y la comunidad. La estrofa purímica -noneta de versos largos y cortos alternados, de rima característica y de una estructura musical particularse presenta en este estudio respondiendo a diversos temas: costumbres y eventos sociales, sucesos históricos y problemas económicos. El presente artículo se dedica a la utilización modélica de esta estructura poético-musical, y se basa en materiales de mi colección catalogados y conservados en la Fonoteca Nacional (National Sound Archives) de Jerusalén.

La versatilidad de la estrofa purímica y su utilización como molde en el cual verter la variedad temática del repertorio coplístico demuestra, una vez más, la vitalidad de la tradición musico-poetica de los sefardíes. A esta utilización modélica se dedica el presente artículo, basado en materiales de mi colección. ${ }^{1}$

La estrofa purímica es uno de los esquemas estróficos de las coplas sefardíes que se escribieron y publicaron ya en la Diáspora, en especial en el siglo XVIII. Los contenidos textuales de las coplas sefardíes se refieren de un modo o de otro, al mundo vivencial de la comunidad judía, ya sea refiriéndose a las fiestas del ciclo anual religioso, a la circuncisión, a la crítica social, cró-

1. Mis encuestas se han efectuado en el marco de mi trabajo en el Centro de Investigaciones de la Música Judía (JMRC), en la Universidad Hebrea de Jerusalen, y todas mis grabaciones se encuentran en la Fonoteca Nacional de la Biblioteca Nacional y Universitaria (National Sound Archives, NSA) a cuyo catálogo se refieren las nomenclaturas que acompañan a cada ejemplo. Las encuestas en España las he realizado como parte del proyecto de investigación en el Departamento de Antropología del Consejo Superior de Investigaciones Científicas, para el cual he contado con el apoyo de la Subdirección General de Promoción de Investigación del Ministerio de Educación y Ciencia de España. Mi agradecimiento a estas instancias.

Anuario Musical, 56 (2001) 
nicas de eventos de la historia del entorno, o aún temas más o menos jocosos. En todo caso, se refieren al mundo judío y concretamente a la vida socio-económica de las comunidades sefardíes en la región otomana o en la marroquí. Las coplas constituyen un género vivo, creativo en su misma escencia, enriqueciendo su corpus en el repertorio sefardí con nuevas coplas que reflejan el impacto de las circunstancias sobre la vida del individuo y la comunidad.

En otras palabras, las coplas sefardíes son una creación postexílica, de contenidos no hispánicos (a diferencia, claro está, del Romancero), formando un repertorio amplio tanto en su cantidad como en su temática. Al ser en esencia un género de tradición libresca, perteneció al ámbito masculino, ya que los hombres, que eran quienes sabían leer, eran tambien quienes entonaban las coplas, leyéndolas (como se diría en sefardí: "meldando") de cuadernillos impresos en las imprentas de Constantinopla, Esmirna, Livorno y, en especial, de Salónica.

En cuanto a su estructura y cohesión temática, las coplas sefardíes, al decir de Jacob M. Hassán, son "poemas estróficos con ilación de contenido (narrativo, descriptivo o expositivo)", con "esquemas estróficos variados pero relativamente limitados" y con distintivos "rasgos formales y de contenido". 2

Concretamente, los contenidos de los textos coplísticos son variados: poemas paralitúrgicos para las fiestas (Purim, Shavuot), para el Brit milah ("de parida”), para indoctrinación moral (admonitivas), ligados a la historia del pueblo judío (coplas de contenido bíblico, influídas por el Talmud), a la historia de la comunidad (sobre acontecimientos reales como incendios, guerras o inmigración), a los cambios de la época (críticas a las modas y a las costumbres). ${ }^{3}$ Todos ellos contenidos de relevancia a la vida de la comunidad y a la articulación de cada uno de sus miembros en la sociedad sefardí.

\section{La estrofa purímica}

La estrofa purímica es llamada así porque precisamente esta estructura se utiliza en varias de las coplas que se cantan en la festividad de Purim, celebrando la salvación de los judíos de Persia por medio de la intervención de la reina Ester, tal como lo relata el libro bíblico de este nombre.

La estrofa purímica consta de nueve versos (una noneta octohexasilábica) en la cual alternan versos largos de ocho sílabas con versos cortos de seis (los versos 1, 3 y 7 son octosilábicos, los demás son hexasilábicos). Estos versos riman: el $1^{\circ}$ con el $3^{\circ}$ (no siempre), en $2^{\circ}$ con el $4^{\circ}$ y el $5^{\circ}$, el6 $6^{\circ}$ con el $7^{\circ}$ y el $8^{\circ}$ con el $9^{\circ}$. El esquema de la rima sería: a-b-a-b-b-c-c-d-d, o, cuando no hay rima entre el $1^{\circ}$ y el $3^{\circ}$, a-b-x-b-b-c-c-d-d (este último es el esquema más frecuente en los ejemplos que se presentan). ${ }^{4}$

2. Hassan "Introducción” a Elena Romero, Coplas Sefardíes, Primera Selección, Córdoba: El almendro, 1988, p. 10.

3. Al repertorio de este tipo creado durante el siglo XX hemos dedicado el tercer CD de la trilogía interpretada por el grupo "Arboleras" (Madrid: Tecnosaga, 2000).

4. Iacob M.Hassan en su tesis doctoral (inedita) sobre las Coplas de Purim (Universidad Complutense de Madrid, Sección de Filología Semítica, Madrid, 1976) explica la versificación de las coplas de Purim y hace notar que en el esquema a-b-a-b-b-c-c-d-d los versos a y c tienen acentuación oxítona. 
La rima es asonante. Hassan hace hincapié en que la rima de las coplas ata los versos no precisamente de acuerdo a la sílaba acentuada sino que muy a menudo se conforma con rimar las últimas sílabas de las palabras, sin considerar si están acentuadas o no. ${ }^{5}$

En cuanto a la música de las estrofas purímicas, podemos decir que ésta sigue con su contorno melódico la estructura formal de la estrofa, articulando las frases musicales en 4 pares: 1 y 2, 3 y 4, 5 y 6, 8 y 9, quedando la 7a frase sola, como en suspenso. En la adecuación de la música con la asimetría del texto podemos notar que, despues de las mencionadas tres parejas de frases musicales complementarias, en los primeros seis versos del texto, la sexta frase termina de un modo particular, ya sea una acentuada línea melódica descendente, una pausa, la nota más baja de toda la canción, etc., anunciando de este modo que en ese punto se quiebra la marcha de frases complementarias, hacia la asimetría de los tres últimos versos: el verso séptimo, que es el discorde, sin pareja que le complemente, y precediendo la última pareja de frases complementarias en los dos versos últimos, octavo y noveno.

Este estudio comprende ocho temas coplísticos, todos ellos en el esquema de la estrofa purímica. ${ }^{6}$ Los tres primeros ejemplos se presentan (en versiones abreviadas) precisamente para conocer las estrofas purímicas como aquellas que le han dado ese nombre: las coplas que se entonan en la celebración de la festividad de Purim. Los cinco temas restantes (dos de ellas en dos versiones) tratan en sus textos de temas de diversos ámbitos: costumbres y eventos sociales, sucesos históricos, problemas económicos. De las tres coplas de Purim que constituyen los tres primeros ejemplos, anoto un fragmento del texto y la música de la estrofa musical.

\section{La historia de Amán y Mardoqueo}

Empezar quero a contar/ hechas del Dio alto

"Complas de Purim al uso viejo"

La historia de Amán y Mardoqueo es la primera copla sefardí impresa (como tal aparece en BAECS), publicada alrededor del año 1700. Sus estrofas van ordenadas según un acróstico alfabético hebreo, y en las estrofas siguientes (la No. 24-34 en la editada por Hassan, según C59,) acróstico del nombre del autor, "amar Abraham hazaq", lo que llevó a Moshe Attias a la conclusión de que se trataba del coplero Abraham Toledo. Fue publicada repetidamente, desde 1730 hasta su impresión en Constantinopla en $1923 .^{7}$

5. Ibid.: “... la identidad de los sonidos finales se establece no a partir de la última vocal acentuada -que en muchos casos sería el último sonido del verso- sino a partir de la última sílaba completa, es decir, comprendiendo también los sonidos consonánticos anteriores al vocálico."

6. Las tres coplas de Purim que se presentan son las Nos. I, XI y XIX en el estudio de Hassán (op. cit.). Vease también el estudio de M. Attias, "Ha-'Komplas de-Purim' be-ladino", Sefunot, II (1958), 331-375 y A. Quilis, "Canciones religiosas, de Pascua y romanzas judeo-españolas", Homenajes: Estudios de Filología Española (Madrid), II (1965), 39-68. Los títulos de las coplas en el presente artículo son los establecidos en Elena Romero, Bibliografía analítica de ediciones de coplas sefardíes, Introducción de Iacob M. Hassán, Madrid, CSIC, 1992 (= BAECS).

7. La historia de Amán y Mardoqueo, Hassán (op. cit.,Copla I) lista treintaicinco textos de esta copla (veintisiete impresos y ocho manuscritos) abarcando desde ca. 1700 hasta 1938. Hassán comenta que esta es "la más extensa y seguramente la más antigua de las Coplas de Purim" (en la versión impresa en Livorno en 1782 tiene ciento doce estrofas!). 
Ejemplo No. 1: La historia de Amán y Mardoqueo

NSA Y 5635b/8 - Shmuel Altalef (Izmir) - Tel Aviv, 4.12.1986

Empezar quero contar

hechas del Dió Alto,

de lo que quero enmentar

nada yo no falto,

con bailes y saltos

y con gran plaćer,

porque Hamán el mamźer

moś quiso matarmoś

tambien atemarmoś.

Oíd lo que aconteció

en tiempo de avante,

de lo que enriqueció,

es cośa de encante,

con un rey gigante

el Ahašveroš;

cantaré con grande ỵoź

y con alegría

esta maravilla.

Empezar quero contar

Shmuel Altalef (J zmir)
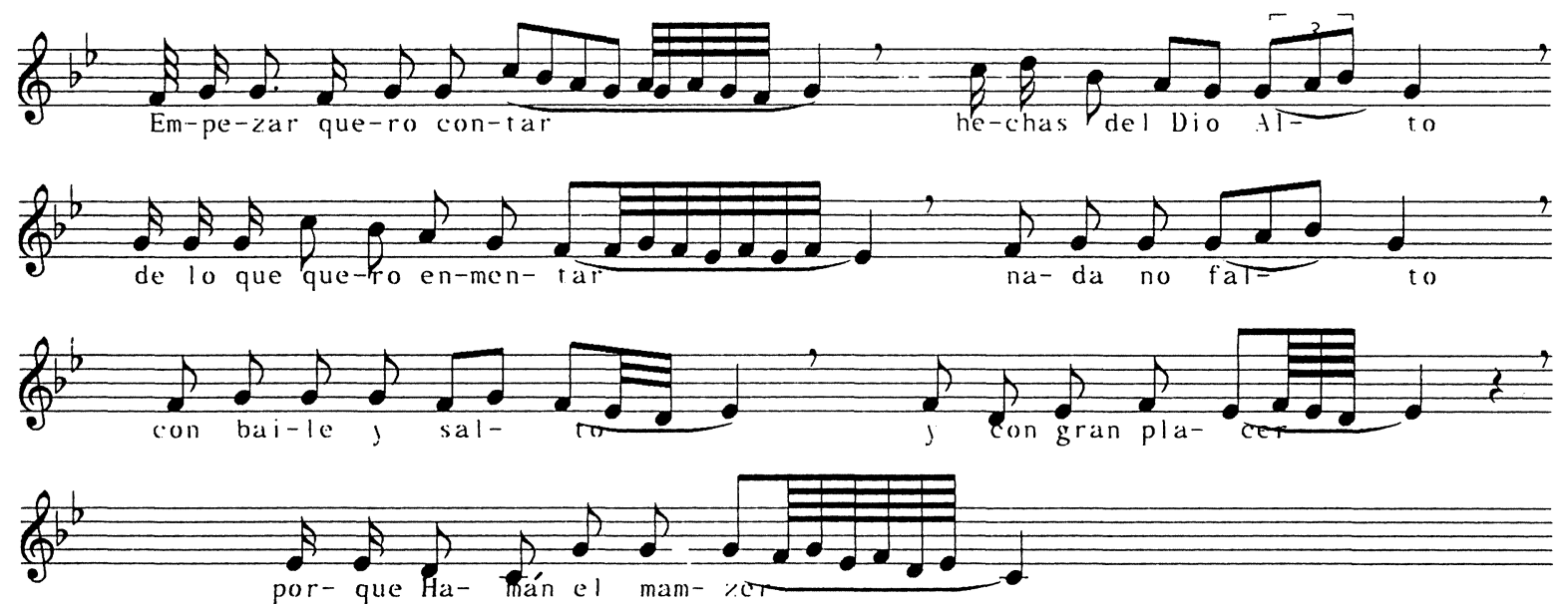


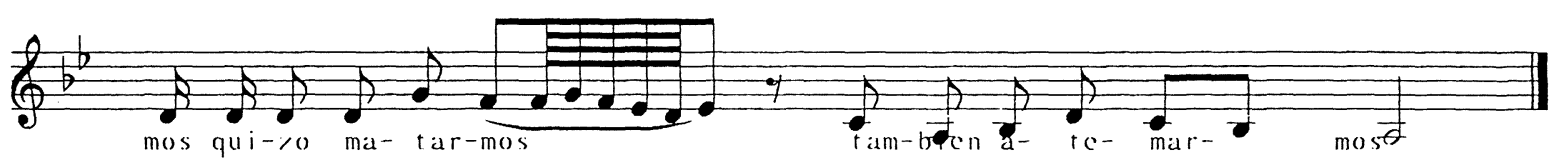

\title{
2. La caída de Amán
}

Empezar quero contar una grande storia

También La caída de Amán tiene sus estrofas ordenadas de acuerdo al acróstico alfabético. ${ }^{8}$ Presentamos parte de una versión oral muy completa (faltan sólo dos letras del acróstico alfabético), debida a la maravillosa memoria de Rosa Avzaradel, de Rodas. ${ }^{9}$ Estas coplas se publicaron repetidamente a partir de su primera impresión en Salónica en 1798. Desde la publicación de 1866 en Salónica y en luego en la de 1884, se titulan Conplas viejas, seguramente para diferenciarlas de las nuevas que ya aparecerían en 1856, en el cuaderno titulado Conplas muevas de Purim siendo agora un año se hicieron... Con el mismo encabezamiento de Conplas viejas se siguen publicando en 1862, 1866, 1873, 1883.

Ejemplo No. 2: NSA Y5823a/1 - Rosa Avzaradel (Rhodes) - Ashdod 6.12.1989

\author{
Empezar quero a contar \\ una grande storia, \\ meter tino y pensar \\ en esta memoria; \\ es una grande gloria \\ que hay de contar: \\ mandaremos a ajuntar, \\ quen es mi amigo \\ que coma conmigo. \\ Bendicho sea el Dio \\ de el alto cielo \\ porque tanta cencia mos dió \\ para conocerlo;
}

8. La caída de Amán, en Hassan, Copla XI, con treinta y nueve estrofas, estudiada en veinticuatro textos (diecinueve impresos y cinco manuscritos) entre 1798 y 1938.

9. Rosa Avzaradel nació en Rodas en 1912, cuando la isla pasó del dominio otomano al italiano; en 1938, con el comienzo de las leyes de discriminación racial por parte del gobierno fascista, fue enviada por sus padres al Congo Belga donde vivió (salvándose de la aniquilación de toda la comunidad judía de Rodas en 1944) hasta 1974, cuando emigró a Israel. Su aporte a mi colección del repertorio sefardí es verdaderamente notable, tanto cuantitativamente como por los textos únicos que recordara. 
en verano y invierno

lo alabaré,

tambien lo bindićiré

tadre y mañana

con toda mi alma.

Gracias daremos al Dió

que nos ha escapado

de las manos de Hamán

Hagaguí, el malo,

él con sus manos

se quiso enramar

y no pudo escapar

de mala setencia,

murió sin dolencia.

\title{
3. La celebración de Purim
}

Alabar quero al Dio/ con tañer y cante (Hassan Coplas XIX)

La celebración de Purim fue compuesta por Sa'adi Halevi en el siglo XIX, impresa en el cuaderno mencionado, Conplas muevas de Purim..., en 1856. Nuestra versión conserva el orden de sus estrofas según acróstico alfabetico, aunque se saltean algunas. ${ }^{10}$

Sin llegar a hacer hincapié en el aspecto linguistico del repertorio (tema digno de un estudio especialmente dedicado a ello) notemos que en esta copla, La celebración de Purim, como en todo el repertorio, se incluyen términos que provienen de otras lenguas, como, por ejemplo, del turco, del hebreo y del italiano. ${ }^{11}$

\section{Ejemplo No. 3: La celebración de Purim}

NSA Yc 1188/8,10. - Yakov Sadikario et al. (Saloniki) - Jerusalem, 4.4.1977.

\author{
Alabar quero al Dió \\ con tañer y cante,
}

10. La celebración de Purim es la No. XIX en Hassan (op. cit.) quien menciona que posee entre veintisiete y veintinueve estrofas y está representada en dieciseis textos (quince impresos y uno manuscrito), entre 1855 y 1938.

11. Vease la alusión a Amán como "hombre berbante" (del italiano: birbante = bribón) y como "mamzer" (del hebreo: ט ט ט bastardo), quien caerá "en una paída" (del griego: paguida = trampa), y por ello, para festejarlo, "debemos de hacer gimbus" (del turco: cumbus = parranda, jolgorio). 
siendo Él no piedrió

amistad avante:

de hombre berbante

Él mos escapó

y a Hamán lo encapó

en una paída,

non topó fuida.

Bušcó Hamán el mamźer

de querer mercarmos,

ésto lo quis̀o hacer

para atemarmos,

no mos olvidamos

esta enemistad:

meldamos con amistad

de la vieja historia

tenelda en memoria.

\section{Lu cel ebrucion de Purim
IAQOOI SADIKARIO (SALONIKI)}
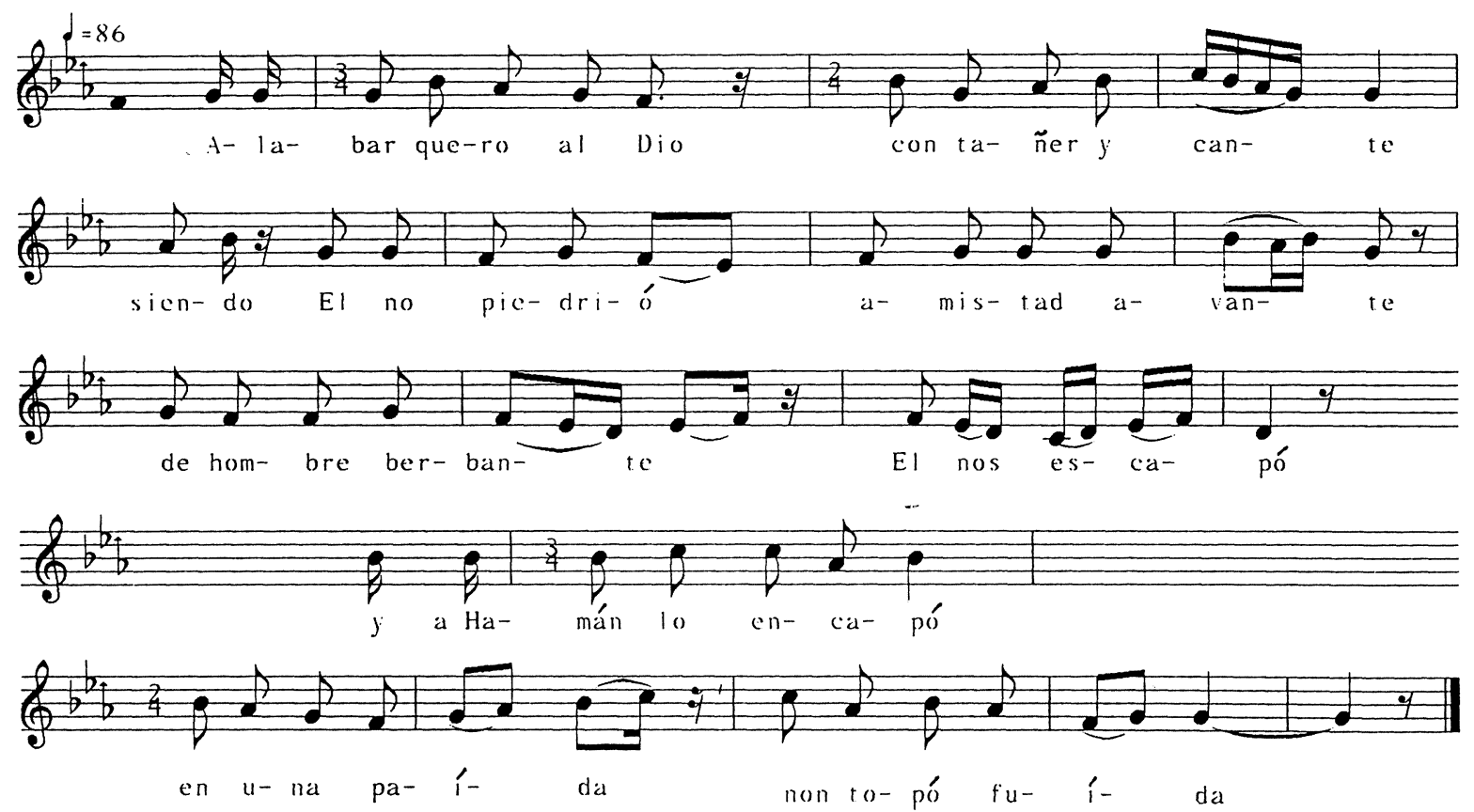


\title{
4. Coplas del incendio
}

En este mismo esquema de noneta octo-hexasilábica se vierte una crónica sobre uno de los incendios que asolaron a las juderías. ${ }^{12}$

La estrofa textual de nuestro ejemplo de la Copla del incendio se asemeja a la estrofa purímica no solamente en el número de versos en la estrofa, sino tambien en el esquema de su rima: los versos Nos. 2, 4 y 5 riman entre sí, los versos Nos. 6 y 7 entre sí, y los Nos. 8 y 9 entre sí. La versión presentada posee seis estrofas, ordenadas según acróstico alfabético de la primera letra en cada estrofa. La estrofa musical, en modo de Do, en un ambitus de una novena mayor, posee, en concordancia con el texto, nueve frases musicales, las dos primeras reiteradas en los últimos dos versos y su repetición.

Ejemplo No. 4: Coplas del incendio

NSA Y5673b/33 - Rosa Avzaradel (Rhodes) - Ashdod, 6.12.1988

\author{
Ano de sešentoś \\ y cuarenta y cuatro \\ fuego en seš de kislev \\ degradó muy alto \\ porque tomimos por manto \\ la ley de tal źimán, \\ olvidimos el šabat \\ y que la ley amiga \\ ella nos abriga. \\ Baavonot que ésto fue \\ negro empesijo, \\ de los cielos abajó \\ este negro gostijo \\ non quedó cortijo \\ ande había meźuźá, \\ quedimos sin camiśa, \\ sin techo y sin banco \\ en medio los campos.
}

12. Sobre el tema de los incendios (y en concreto de uno posterior al de nuestro ejemplo, que asoló Salónica en 1917) y su reflejo en el repertorio coplístico véase el artículo de Shmuel Refael, "Los cantes del incendio", Ladinar I (1998): 93-118. 
Grande derrocamiento fue para el probe y el rico el guevir y el eźnav todos a un pico el governo rico el rey Sultan Hamid mandó muchos źabit que miren la manćía de la judería.

Dádivas mandó el rey cinco mil ducados que miren de arremediar a todos los quemados, los más entiźnados sin tener valor la luvia y la hielor en pies, muertos de hambre, ya moś abajó calambre.

El Dió ya moś amostró señal temerośo fuego del cielo abajó sin tener repośo pierdimos el goźo y el rahatlik más y más el keśatlik en las kišláś echados como peceś salados.

Vergas de fuego echó el Dió de los cielos, a los chiquiticos quemó como los burmuelos, viejos y mancebos en bajo asentad, los ojicos atentad, ésto fue negra saña de parir en las montañas. 

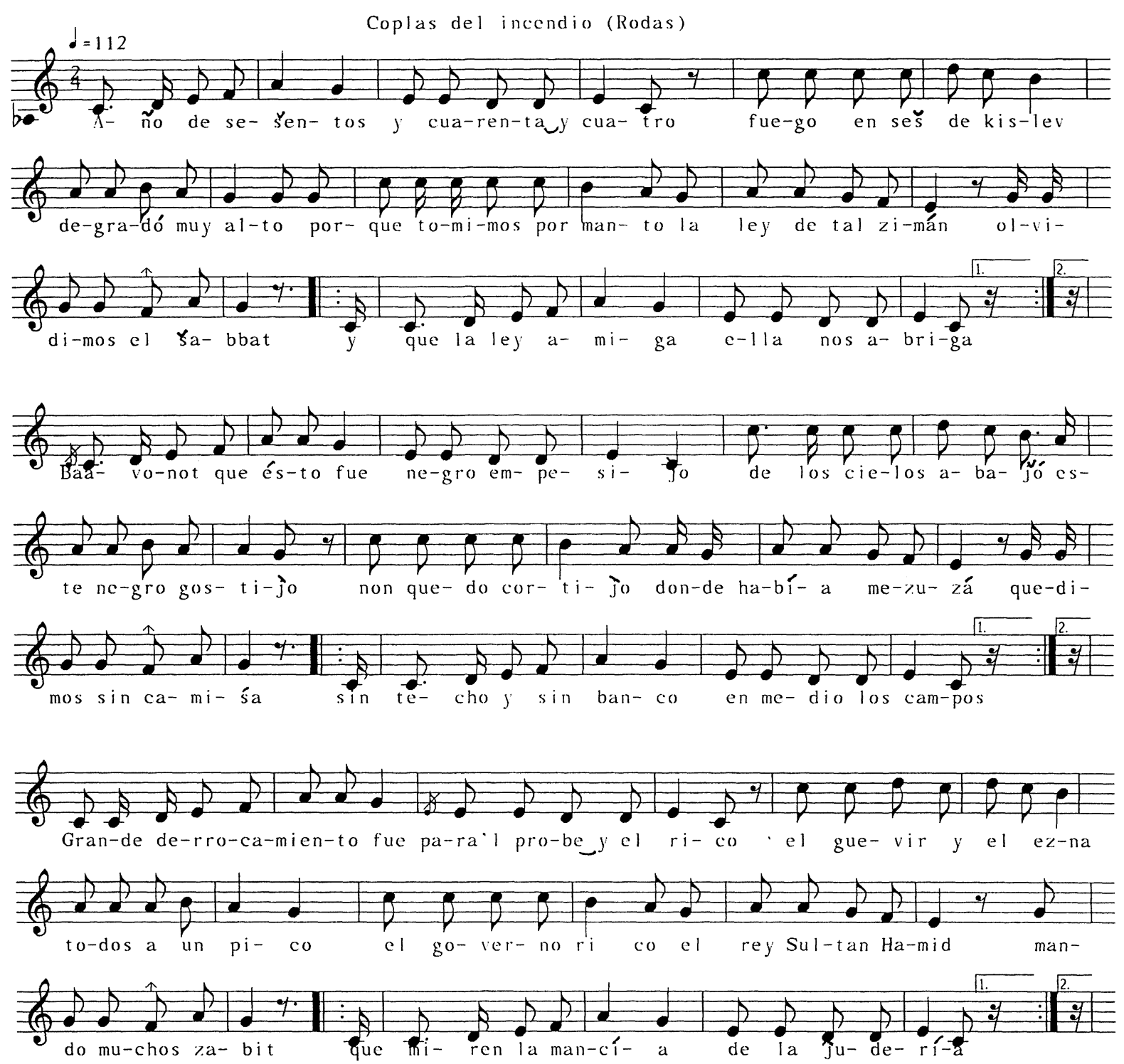

El incendio del cual habla esta copla habría sucedido en 1883, según lo dice su incipit: "Año de sešentos y cuarenta cuatro" del calendario hebreo, y aún cita la fecha exacta: el día "seš" del mes de "Kislev", mes del calendario hebreo que correspondería al mes de noviembre o diciembre. Otro dato de inferencia histórica se da en la tercera estrofa, donde se menciona al Sultán Hamid, refiriendose al Sultán Abdul Hamid II, quien reinó en los años 1876-1909.

El texto se refiere a uno de los tantos incendios que afectaron a las juderías en los siglos XVIII, XIX y principios del XX. Además de reflejar la tremenda desgracia, porta una intención 
didáctica y moralizadora, adjudicando el incendio de la judería al abandono de la religión y de la moral. $^{13}$

Digna de notar es la abundancia de términos de procedencia turca, incluídos en el judeoespañol durante los años en que los judíos vivieran bajo el dominio otomano y que, significativamente, son más frecuentes en las coplas que en los romances. ${ }^{14}$

Nuestra versión tiene seis estrofas ordenadas de acuerdo al alfabeto hebreo en el cual se solía escribir el judeo-español, en escritura aljamiada, de modo que cada estrofa comienza con la letra siguiente del alfabeto. Cada estrofa del texto posee los nueve versos que caracterizan, junto con el esquema de su rima, a las coplas purímicas, alternando versos cortos y largos de número variado de sílabas (de 6 o 7 y de 8 o 9 sílabas, variaciones típicas del repertorio coplístico), encuadrados en la melodía por medio de la utilización de valores rítmicos adecuados (para compararlos, veanse los compases Nos. 1 y 9 en las tres estrofas que se presentan).

La estrofa musical, en modo de Do, en un ambitus de una novena mayor, posee, en concordancia con el texto, nueve frases musicales, las dos primeras repetidas en los últimos dos versos y su reiteración. La melodía está en modo mayor, en un ambitus de una novena mayor, y su ritmo en un compás de $2 / 4$.

$\begin{array}{lccccccccccc}\text { Número del verso: } & 1 & 2 & 3 & 4 & 5 & 6 & 7 & 8 & 9 & 8 & 9 \\ \text { Esquema de la rima: } & \text { a } & \text { b } & \text { x } & \text { b } & \text { b } & \text { c } & \text { c } & \text { d } & \text { d } & \text { d } & \text { d } \\ \text { Estructura melódica: } & \text { A } & \text { B } & \text { C } & \text { D } & \text { C } & \text { E } & \text { F } & \text { A } & \text { B } & \text { A } & \text { B } \\ \text { Cadencias de las frases: } & \text { V } & \text { I } & \text { VII } & \text { V } & \text { VI } & \text { III } & \text { V } & \text { V } & \text { I } & \text { V } & \text { I }\end{array}$

\section{Consejos a un muchacho}

De èsta copla se anotan aquí dos versiones fragmentarias, una de Dupnitze (5a), y otra de Saloniki (5b) que se complementan. ${ }^{15}$ En estas coplas se resumen los valores básicos de la comunidad sefardí, ofreciendo (desde la 1a. estrofa de 5a) buenos consejos y guía moral para el muchacho en cuanto a relaciones sociales (tratar a todos con dulzura y con igual respeto, estrofa 2a. de 5a). ${ }^{16}$ En la versión 5 b, un compendio de los conceptos de la sociedad sefardí: ser hacendoso y madrugador, cuidar la higiene personal y los preceptos de la religión, la dedicación al tra-

13. Así finaliza la copla, en sus últimos versos que aluden a los partos indeseados (jovenes solteras o adúlteras) y ocultados: "esto fue negra saña / de parir en las muntañas".

14. Requieren explicación los términos que deriven del hebreo y del turco: zimán = tiempo (del hebreo: zeman); šabat $=$ sábado; baavonot $=$ por los pecados; gostijo = gusto; mezuzá $=($ heb.) pequeño estuche que el judío fija en la jamba derecha de la puerta de casa y de otras puertas, y que tiene en su interior un pequeño rollo de pergamino donde van escritos versículos del Deuteronomio y una plegaria hebrea; gevir = rico (heb.); eznav = clase media (tur.); $z a b i t=$ policías (tur.); judería = barrio judío; rahatlik = bienestar (tur.); kesatlik= mala situación económica (tur.); kišlas = casernas (tur.).

15. Esta copla está catalogada en Samuel G. Armistead, El Romancero judeo-español en el Archivo Menéndez Pidal, Catálogo - Indice (Madrid: Cátedra Seminario Menéndez Pidal, 1978) como AA84 y AA86. Para un estudio de esta copla, vease Elena Romero, Coplas Sefardíes, Primera selección, Córdoba, Ediciones El almendro, No. 15, pp. 127-130.

16. Dice: todos a un pico (pico: medida de longitud), es decir, medir a todos con una misma medida, sin tomar en cuenta si es rico o pobre (como en la copla anterior, Ejemplo $N^{\circ} 4,3^{a}$ estrofa). Nótese la influencia francesa en elevo $=$ muchacho en edad escolar (del fr. eleve) 
bajo $^{17}$ (1a. estrofa) y, cuando crezca, elegir su esposa de acuerdo a los criterios respetados por su sociedad ( $2^{\mathrm{a}}$ estrofa).

La música otrece las características señaladas, con la asimetría de su séptima frase musical (con el séptimo verso) que después de la serie de pares de frases aparece como unidad de una frase sola que cadencia en el $5^{\circ}$ grado.

Ejemplo No. 5: Consejos a un muchacho

5a. NSA Y 6536d/1 - Dora Conforti (Dupnitze) - Yaffo, 22.3.1999

Hijo de poca edat

siente mi doctrino

tómalo en corazón

mételo en tino,

como l'oro fino

que es volutośo,

sea privichośo

agora soś elevo

di bien y mancebo.

Boca dulce siempre ten

con grande y chico,

no tengas deferencie

del prove n'al rico,

con un meśmo pico

todos meśuralos, con bien ta figura, al rico lo ar'bajo, al probe lo enšalžo.

5b. NSA Y 5982b/2, Hanna Malaj-Sadikario (Saloniki) - Givatayim, 1.6.1992

Mira, ver de madrugar

y d'alevantarte, primo hecho que harás:

la cara lavarte y dempués andarte

17. El término hecho: si bien parece el participio pasado del verbo hacer, es posible que provenga de "ich" (ic, tur.) que significa "trabajo, profesión, ocupación". 

a la santa kehilá
a demandar piadá, te irás al hecho,
te verás provecho.
Mancebo te hićites, por tomar esposa no te engañes de parás ni de facha hermośa:
sea venturośa y dulce en el hablar, sea de casta alta, si es de familla te salva la vida.

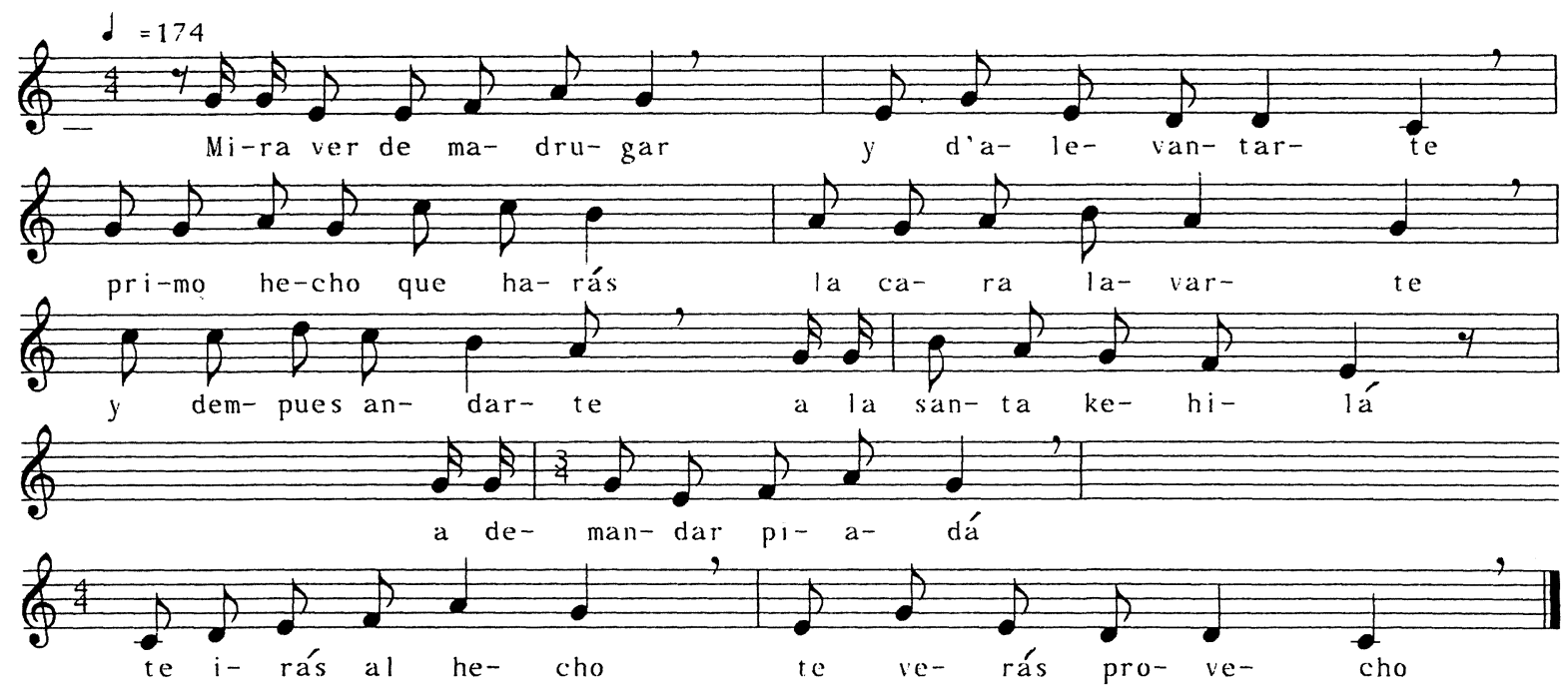

\section{Quejas de recién casada}

Esta copla presenta los lamentos de una recién casada (palizas e insultos) y las quejas contra su suegra, con quien tiene que vivir la joven pareja, como era frecuente en las comunidades de los Balcanes: ella prefiere separarse (quitación) ya que la convivencia es difícil, y la suegra hasta (afilu, heb.) ha logrado enemistarla con su marido. 
Ejemplo No. 6: Quejas de recién casada

NSA Yc 1599/26, Suzanne Avigdor (Istamboul) . Rec. Yaffo, 7-1-1979

Haftoná y maldición de recín caśada, me contento quitación y no star caśada, ya sto una trocada de cuando caśí; ya lo dije cuando spośí: cuando oyí esfuegra la vivienda es negra.

Que mire siñor padre que mire este rijo, a la tadre que venga, que prunte al cortijo, afilu al hijo ya lo malmetió hasta que m'aborreció; no quero marido, anque es $\tan$ querido.

Quejas de recien casada HANNA MALAJ-SADIKARIO (SALONIKI)

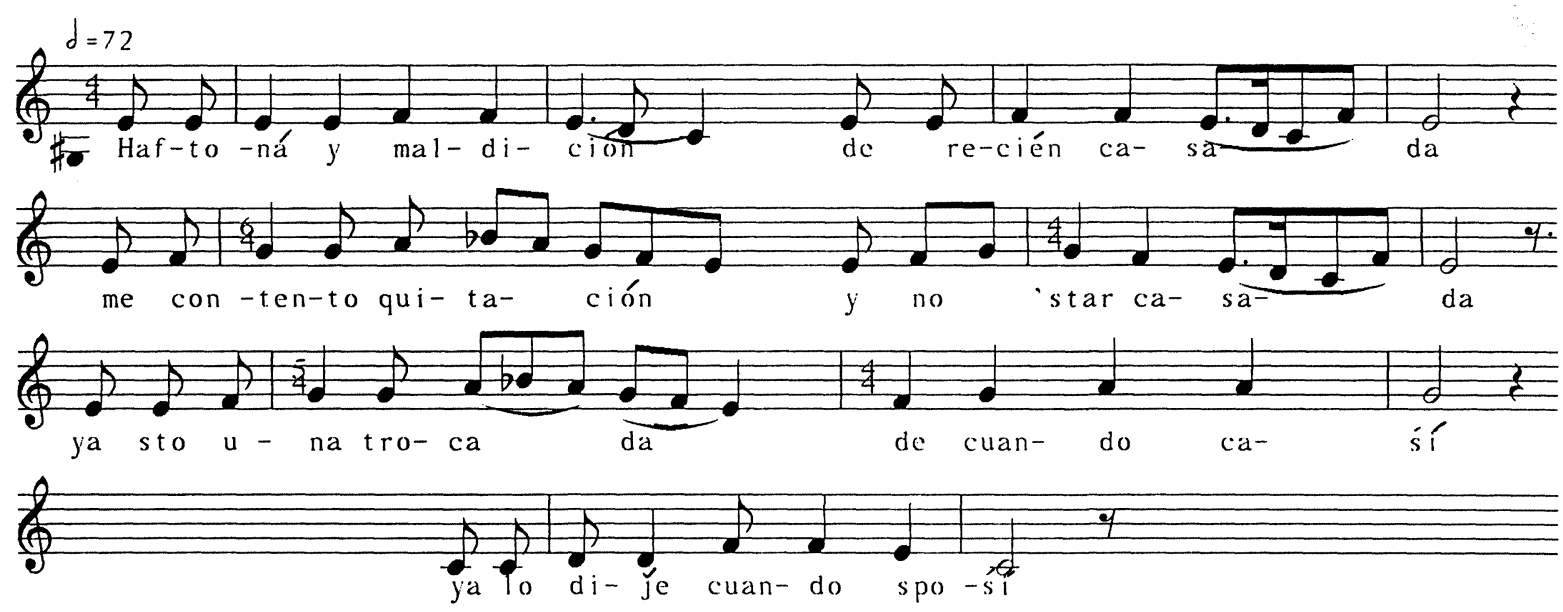




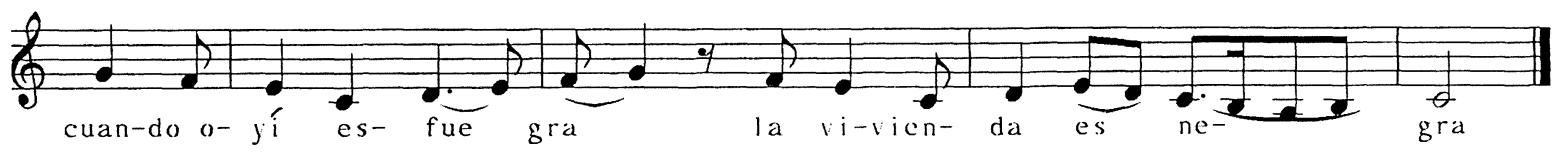

\section{Adulterio escandaloso o Los amoríos de Esterina Sarfatí}

Un verdadero escándalo social, los amores ilícitos de Esterina con un hombre casado que por ella (a quien se refiere "que se la lleve el guerco", es decir, el demonio) y por sus coqueterías (la jillvé) se ha separado (se quitó) de su mujer y de su hijo. ${ }^{18}$

Presentamos una versión de Estambul. Agregamos aquí, para ilustrar la difusión de esta copla, la transcripción musical de otra versión de Chanakalé.

También aquí el verso siete cadencia sobre el $5^{\circ}$ grado, la dominante.

Ejemplo No. 7: Los amoríos de Esterina Sarfatí

NSA Y5995a/7, Dora Levy (Istamboul) Rec. Rishon Letsion, 29-5-1992

Esterica Serfati

l'amor está haciendo

por Davicho el borrachó

ya se sta muriendo.

Le sta pareciendo

que no se le va a saber:

se quitó de la mujer,

pecado en su alma,

el güerco le lleve l'alma.

-Ah, Davicho, mi alma, ¿de qué vienes tadre?

El hijo se va a morir, quere ver al padre.

-Cośa que no m'hinche

del hijo y de vos, (2)

yo quero a Esterica,

que es entera mía.

Al deré a caminar,

a poco, a poco,

18. Esta copla es muy conocida en todas las comunidades del área otomana y, curiosamente, cada vez que ha sido grabada, las informantes declararon que habían conocido personalmente a los personajes que se mencionan. 
la jillvé que le haće

ya lo quita loco

ya lo quita loco

y de su meollo,

este lo compośí yo:

me topí solica,

lo asentí cantica.

tdulterio escundaloso

DORA LEVY (ISTANBUL)
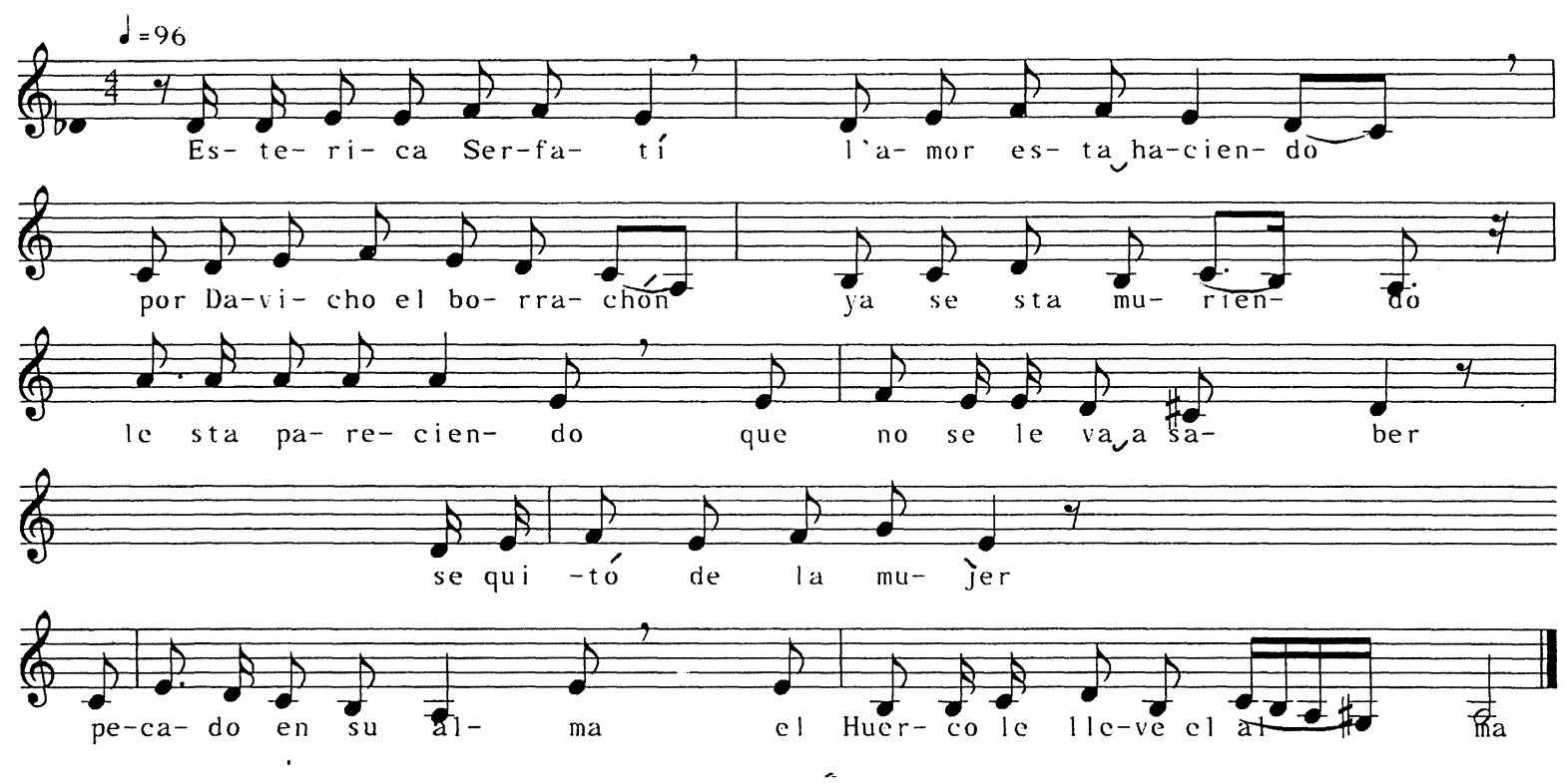

\section{El precio del café}

El último ejemplo ofrece dos versiones del tema del aumento del precio del café que, al convertirse en prohibitivo (en la primera estrofa de cada versión) obliga a utilizar sucedáneos (garbanzos tostados en vez de café). A través de este tema, y en especial en las estrofas siguientes en la segunda versión, se traslucen las dificultades económicas, la preocupación diaria de alimentar a los hijos y aún la modesta elección de comidas ("habicas secas") ya que si pregunta en la tienda (bakal, tur.) por la fruta del tiempo (trufandá, tur.) está claro que es demasiado cara para el pobre (aní, heb.).

La música mantiene la típica estructura formal de las coplas purímicas: tres parejas de frases (pregunta y respuesta) terminando en un descanso o nota de mayor duración, luego una frase única (para el séptimo verso) y otra pareja de frases para concluír. 
Ejemplo No. 8: El precio del café

8a. Haim Dassa (Saloniki), Jerusalem, 8.6.1977, NSA Yc1215/32

El cavé ya pujó

a treinta y dos y medio, tosta garbanzo y bebe, que no tenes̀ remedio, sin dotar pan y medio no vos podes̀ pasar; la vićina ya lo ve, cavé como tengo el día me mantengo.

\section{EL CAVE YA PUJ̌́ - HAIM DASSA (SALONIKI)}

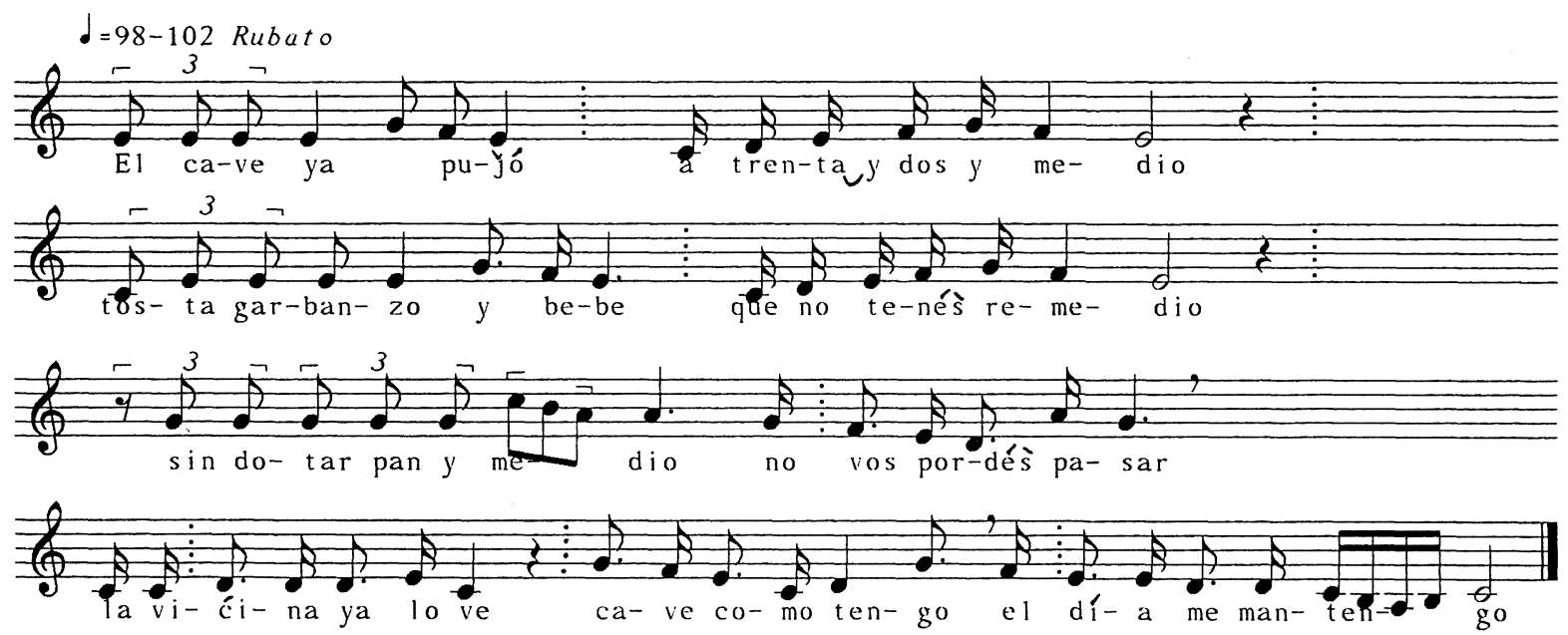

A TRENTA GROSES CAFE - ALEGRE HALI0-MUSABAK (CHANAKALE)

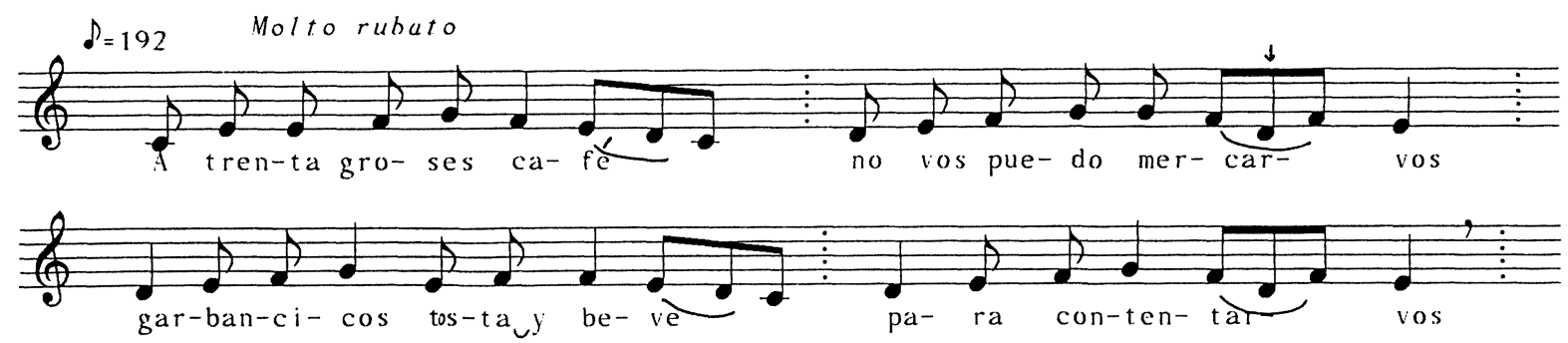




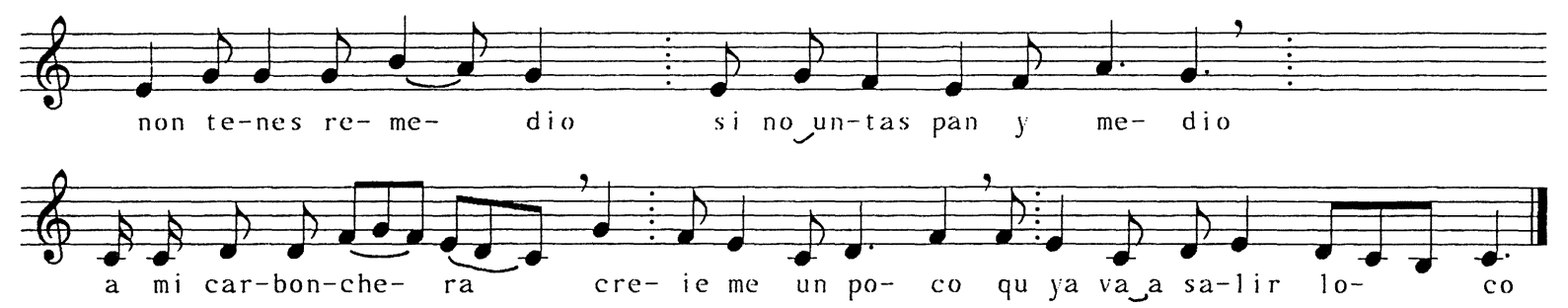

8b. Alegre Halío-Musabak (Chanakale), Nes Siona, 22.5.1998, NSA Y 6486b/4

A trenta grošes cavé no vos puedo mercarvos, garbancicos tosta y bebe para contentarvos, no tenes remedio, si n'untas pan y medio, ah, mi karbonchera, créeme un poco, que ya v' a salir loco.

Pensa, la nikochera, a la demañana, a los hijos qué darás ah, la desmaźalada, su buena pasada es un finjan de cavé, la vićina ya lo ve: kavé como tengo, día 'ntero me mantengo.

La comida del aní es habicas secas, non come el benoní nunca pan a secas, en tiempo de frescas y de trufandá anda pregunta al bakal, vos mira en la cara, vos diće que sta cara. 
Para concluir, podremos apreciar la proximidad formal y aún melódica de algunos de los temas presentados, ordenados seguidamente en una comparación paradigmática:

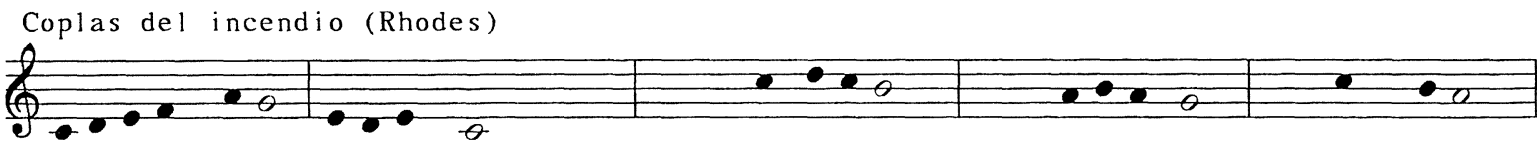

Consejos a un muchacho

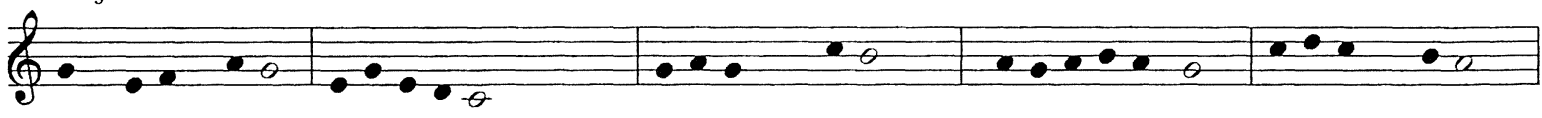

Quejas de la recien casada

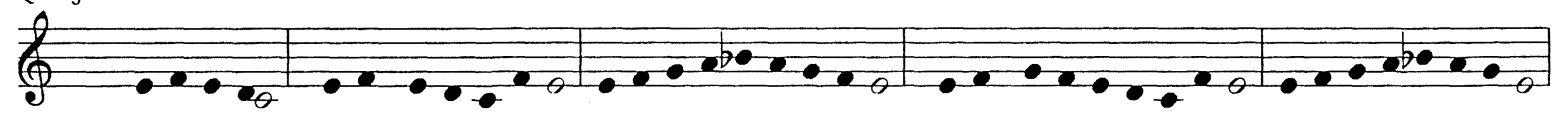

Adulterio escandaloso

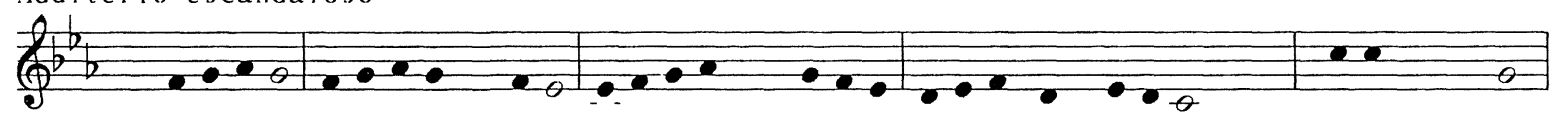

Coplas del incendio (cont.)

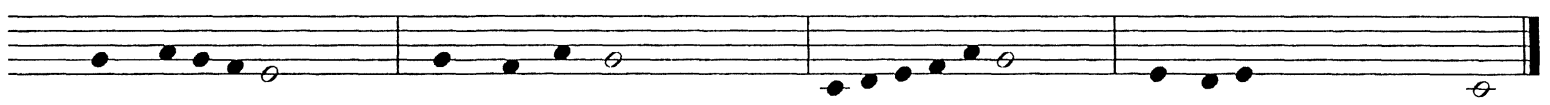

Consejos a un muchacho (cont.)

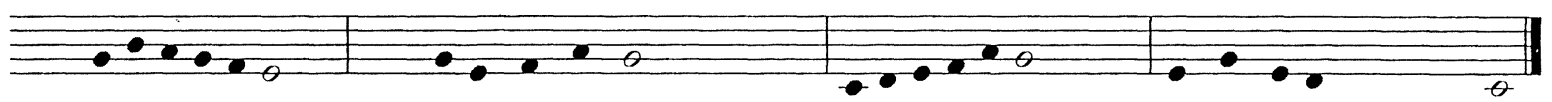

Quejas de la recien casada (cont.)

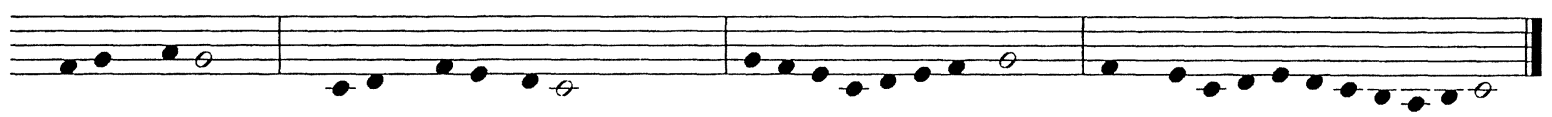

Adulterio escandaloso (cont.)

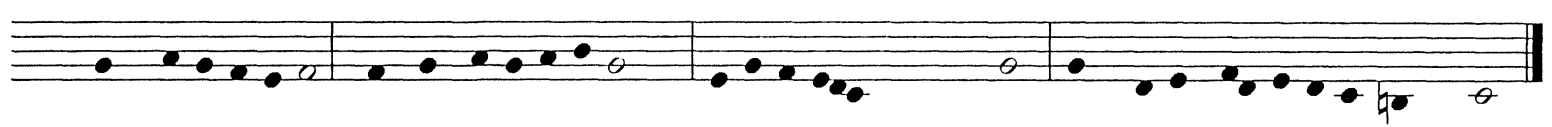

Dentro de la variedad de sus melodías, mantienen todas las coplas presentadas una clara uniformidad en cuanto a su estructura formal y a las técnicas musicales que sirven para adaptar la música a la estructura asimétrica del texto. Desde el punto de vista de la antropología musical, los cinco temas que utilizan la estructura de la copla purímica nos ofrecen, además de su interés musical, una visión de las comunidades sefardíes, sus problemas, sus preocupaciones, 
sus vivencias y sus valores, volcados en coplas de diversos contenidos: crónicas de eventos históricos, consejos morales y prácticos destinados a la generación siguiente, desde descripciones de incendios, a problemas de la recién casada, hasta un caso de adulterio escandaloso y del aumento de los precios. Un panorama de temas vivenciales en un esquema tradicional de versificación. 